\title{
Minimally invasive spine surgery: An alternate corridor for various spinal procedures - Our institute experience
}

\author{
Bijukrishnan R. ${ }^{1}$, Shaji U. A. ${ }^{2}$, Sreenath K.,"* \\ ${ }^{1}$ Professor, ${ }^{2}$ Assistant Professor, ${ }^{3}$ Senior Resident, Dept. of Neurosurgery, Government Medical College, Thrissur, Kerala, \\ India
}

*Corresponding Author:

Email: drksreenath@gmail.com

\begin{abstract}
Introduction: Minimally invasive spine procedures are minimally destructive procedures which minimizes surgery related morbidity by avoiding excessive muscle dissection and reduce tissue trauma during surgery. The indications of these procedures are increased significantly these days.

Aim: To report our experience with minimally invasive spine surgery for various spinal procedures.

Materials and Methods: This is an observational study done from 2016 to 2018, in the department of Neurosurgery, Government medical college, Thrissur. We randomly selected 35 patients, who underwent various minimally invasive spine procedures, which include 15 lumbar discectomy (9 L5S1, 5 L45, 1 L34), 10 pedicle screw fixation (both dorsal and lumbar) and 10 IDEM spinal tumours.

Results: Mean age of patients was 45.72 years. Most of them were in between 20 to 60 years of age with 20 males (57.14\%) and 15 females (42.85\%). Mean blood loss was $105 \mathrm{ml}$ for discectomy, $125 \mathrm{ml}$ for pedicle screw fixation and $154 \mathrm{ml}$ for IDEM tumour excision and no patient required blood transfusion. Average duration of procedure was 95 minutes for disc prolapse, 150 minutes for fracture fixation and 190 minutes for spine tumour excision. Average number of shots of $\mathrm{C}$ arm exposure was 6 for IVDP, 38 for fracture fixation and 6 for spine tumour excision. All Junior neurosurgeons of our department performed at least one discectomy or pedicle screw fixation without much difference in duration or outcome but surgeons with enough experience in open spinal procedures or spine tumour excision were required for all spine tumour excision cases. Improved pain score was noted during post operative period. Two patients developed CSF leak and mild postoperative wound infection which was managed conservatively. No patient developed new onset neurological deficits, bowel or bladder involvement in the post operative period.

Conclusions: We observed that minimally invasive spine surgery is safe and less destructive. The procedure is fast and associated with minimal morbidity and no mortality. We also noticed that there is increased risk for radiation associated with minimally invasive pedicle screw fixation. There is no significant learning curve associated with pedicle screw fixation or lumbar discectomy but it is significant in case of minimally invasive spine tumour excision.
\end{abstract}

Keywords: Minimally invasive, Spine surgery, Tubular retractor.

\section{Introduction}

The earliest report of modern minimally invasive spine surgery was a case of lumbar discectomy done with a newly made tubular retractor system for the access of lumbar spine. ${ }^{1}$ Minimally invasive spine surgery using this unilateral dilation technique and selfretaining tubular retractor system is becoming popular now among surgeons for discectomy for herniated disc, pedicle screw fixation for spine fracture, inter body fusion or spine tumour excision. Less muscle dissection reduces iatrogenic tissue trauma during surgery and minimizes approach related morbidity associated with surgery. The benefits over traditional open surgery include smaller incisions, less soft tissue damage, reduced estimated blood loss, decreased postoperative pain, shorter hospital length of stay, faster recovery and quicker return to work. ${ }^{2-4}$ In our institute we do minimally invasive spine procedures such as minimally invasive lumbar discectomy, pedicle screw fixation for traumatic spine fracture and intradural tumour excision. This study to report our institute experience with minimally invasive spine surgery for various spinal procedures.

\section{Materials and Methods}

This is a observational study done from 2016 to 2018. This study was conducted in the department of Neurosurgery, Government medical college, Thrissur. The aim of this study is to report our experience with minimally invasive spine surgery for various spinal procedures. We randomly selected 35 patients, who underwent minimally invasive spine procedures, which include 15 lumbar discectomy (9 L5S1, 5 L45, 1 L34), 10 pedicle screw fixation (both dorsal and lumbar) and 10 IDEM spinal tumours. Patients include 20 males and 15 females. Cases included were Herniated lumbar disc, Single or two level lumbar spinal tumours and spine fracture without significant neurological deficits. Patients with severe spinal canal stenosis, fracture causing significant cord compression or paraplegia and long segment spinal tumours were excluded from the study. We used minimally invasive spine surgery set consisting of serial dilators, tubular retractor system and minimally invasive pedicle screws and rod set manufactured by Jayon surgicals, Palakad, Kerala, India and C- arm and microscope wherever needed. 
Patient demographic data was recorded. Amount of blood loss was estimated by measuring the amount of blood collected in the suction jar with adjusted corrections for the saline used. Number of $\mathrm{C}$ arm exposures was directly recorded for individual patients during the procedures. Visual analogue score was recorded during post operative period to assess the pain.

\section{Methodology}
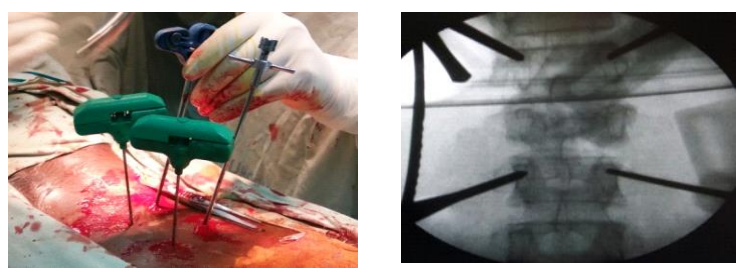

Fig. 1.1: Locating the pedicle
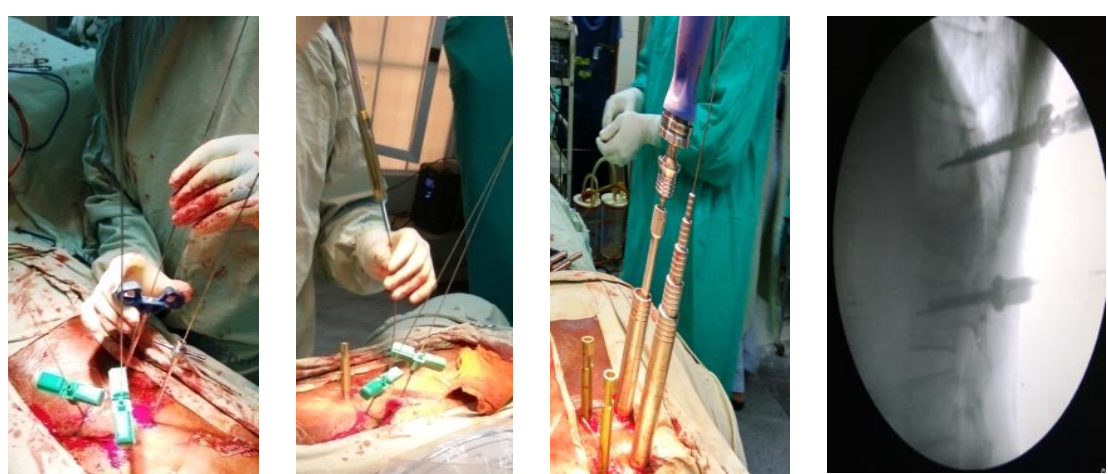

Fig. 1.2: K-wire fixed on the pedicle over which pedicle screws are inserted after serial dilation, Confirmation of position with $\mathrm{C}$ arm
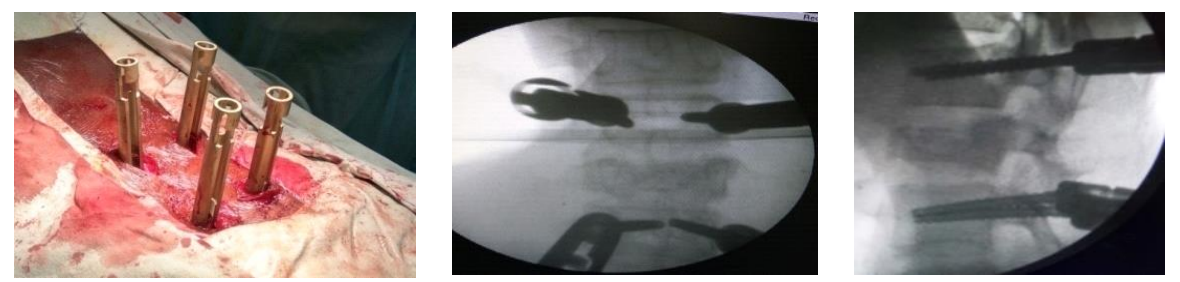

Fig. 1.3: Final position of 4 screws and $C$ arm confirmation
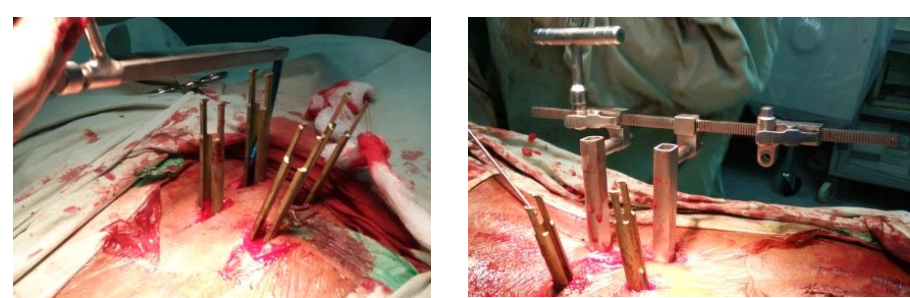

Fig. 1.4: Insertion of curved rods with a special rod holder\& distraction can be done if required 
Fig. 1.5: Final construct

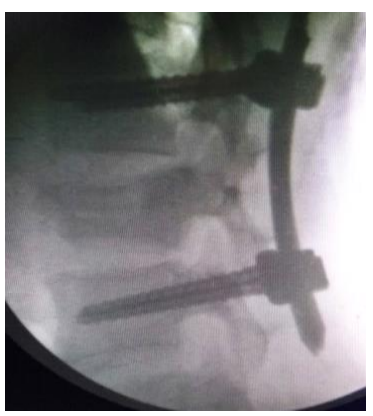

Fig. 1.1-1.5: Steps of Pedicle screw fixation

For discectomy or tumour excision (Fig. 2.1-2.4): Apply the retractor system at the correct space and this should be confirmed with AP and lateral c arm exposure. Next step is to do laminectomy and bring microscope into the field. At this point discectomy or tumour excision can be performed. For tumour excision dura is opened by splitting the dura and tumour excision can be achieved under microscope. Dura is closed with continuous or interrupted 5-0 polypropelene sutures and fibrin glue applied in all tumour excision cases to make the dural closure perfect.
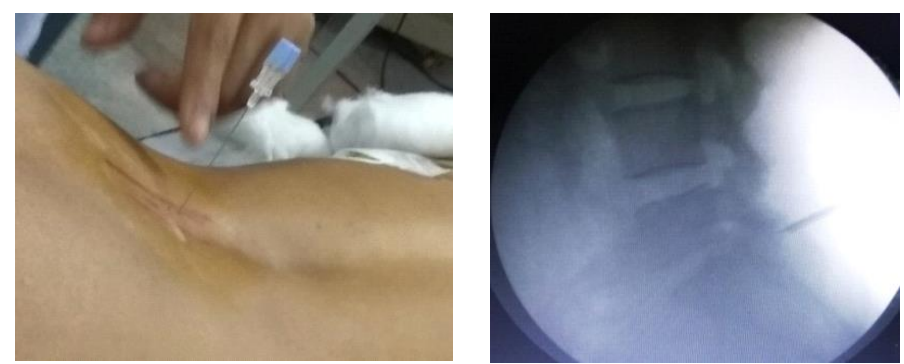

Fig. 2.1: Locating space and pedicle
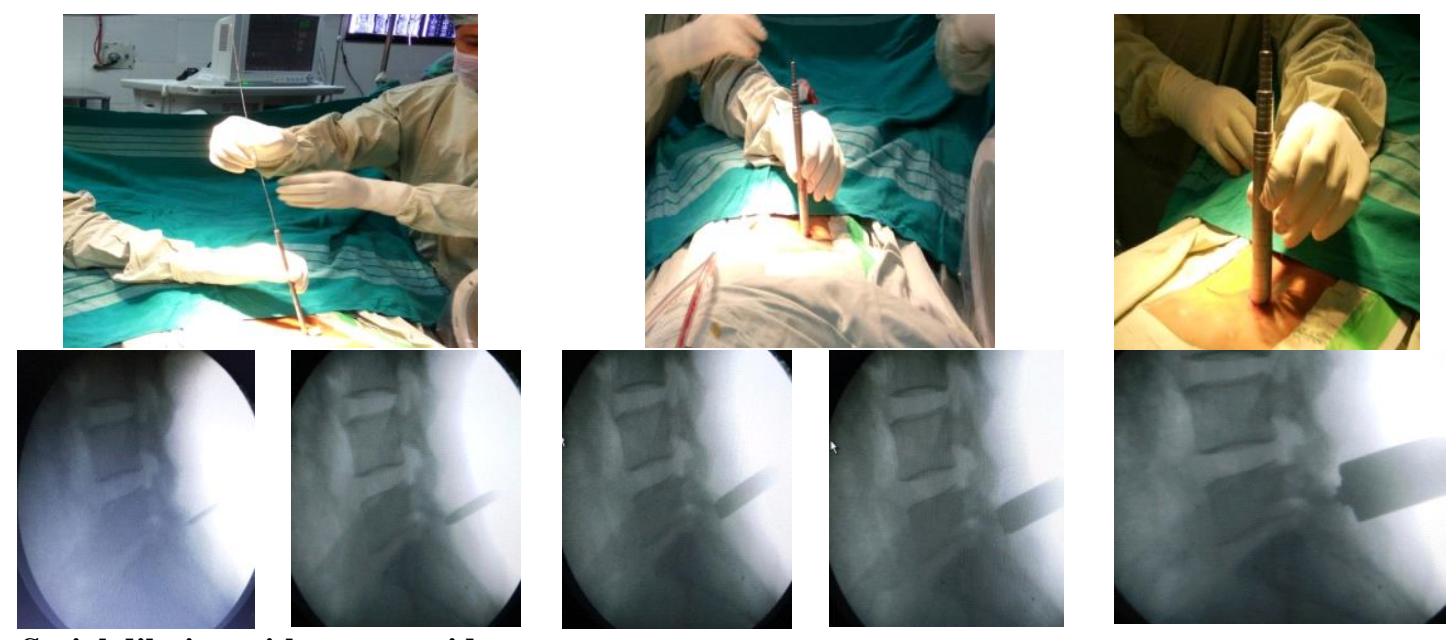

Fig. 2.2: Serial dilation with c-arm guidance
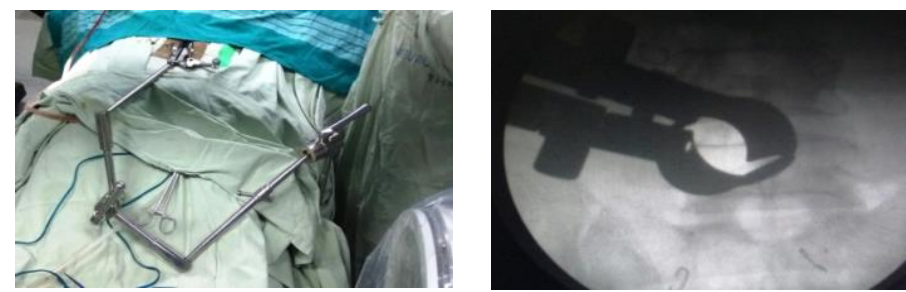

Fig. 2.3: Applying tubular retractor system 

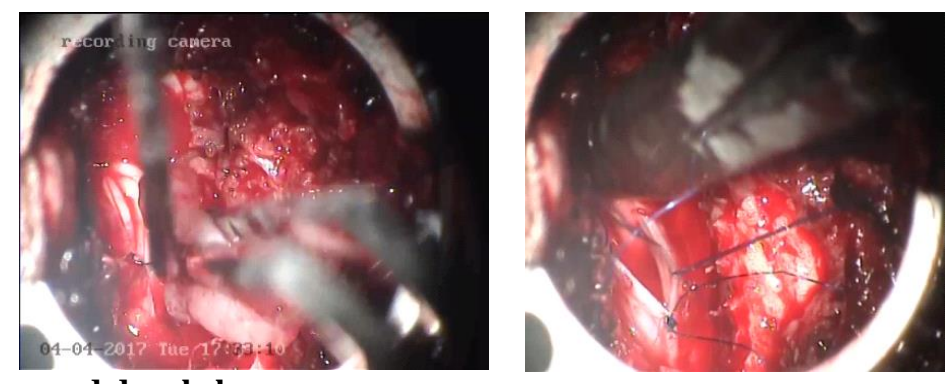

Fig. 2.4 Tumour excision and dural closure

Fig. 2.1-2.4: Steps of discectomy or tumour excision

\section{Results of the study}

Mean age was 45.72 years. Most of them were in between 20 to 60 years of age with 20 males $(57.14 \%)$ and 15 females(42.85\%). Mean blood loss was $105 \mathrm{ml}$ for discectomy, $125 \mathrm{ml}$ for pedicle screw fixation and $154 \mathrm{ml}$ for IDEM tumour excision and no patient required blood transfusion. Muscle dissection or tissue destruction (Fig. 3) was very minimal. Average duration of procedure was 95 minutes for disc prolapse, 150 minutes for fracture fixation and 190 minutes for spine tumour excision (Table 1). Average number of shots of $\mathrm{C}$ arm exposure was 6 for MIS discectomy, 38 for fracture fixation and 6 for spine tumour excision (Table 2). All junior neurosurgeons of our department performed at least one discectomy or pedicle screw fixation without much difference in duration or outcome but surgeons with enough experience in open spinal procedures or spine tumour excision were required for all spine tumour excision cases.
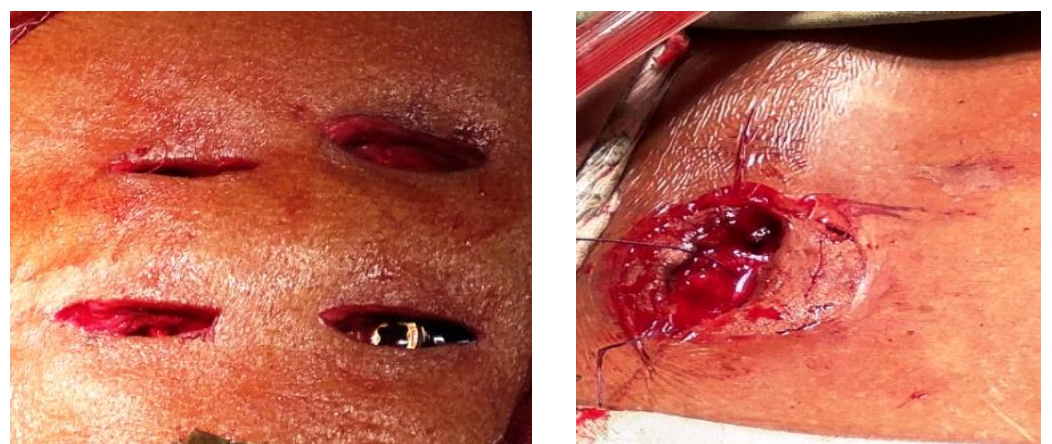

Fig. 3: Minimal muscle dissection; 3.1): Muscle dissection in pedicle screw fixation; 3.2): Muscle dissection in tumour excision

Table 1: Duration of procedure

\begin{tabular}{|c|c|c|c|}
\hline Procedure & Minimum(hr) & Maximum(Hr) & Average $(\mathrm{Hr})$ \\
\hline IVDP & 1.25 & 2.15 & 1.35 \\
\hline Fracture Fixation & 1.45 & $3.10^{*}$ & 2.30 \\
\hline Tumour & 2.25 & 5.35 & 3.10 \\
\hline
\end{tabular}

*Two level fracture (T8 \& L1)

Table 2: C arm exposure (no of shots)

\begin{tabular}{|l|c|c|c|}
\hline C arm exposure & Minimum & Maximum & Average \\
\hline IVDP & 4 & 8 & 6 \\
\hline Fracture Fixation & 25 & 64 & 38 \\
\hline Tumour & 5 & 8 & 6 \\
\hline
\end{tabular}

Visual analogue scale (VAS) was used to assess post operative pain. VAS ranges from 0-10(0-nopain, 2-mild annoying pain,4-nagging, uncomfortable, trouble some pain; 6-Distressing, miserable pain;8-intense, dreadful, horrible pain;10-worst possible, unbearable excruciating pain). Improved pain score was noted during post operative period (Table 3). No patient gave a scale which is more than 4 at any point of time after surgery. Average length of incision was $2.7 \mathrm{cms}$ (Fig. 4). 

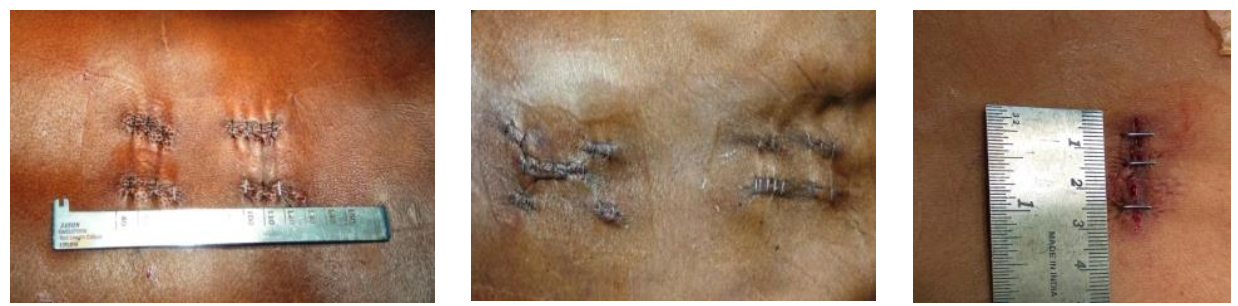

Fig. 4: Improved Cosmesis; 4.1): Pedicle screw fixation-single level spine fracture; 4.2): Pedicle screw fixation of two level fracture (T7\&L1) with Laminectomy in the lower level through a small seperate midline incision; 4.3): Spine tumour excision

Table 3: Post operative VAS Score

\begin{tabular}{|l|c|c|c|}
\hline VAS Score & $\mathbf{1}^{\text {st }}$ POD & $\mathbf{2}^{\text {nd }}$ POD & $\mathbf{3}^{\text {rd }}$ POD \\
\hline 0 & 4 & 20 & 2 \\
\hline 2 & 25 & 13 & 1 \\
\hline 4 & 6 & - & - \\
\hline
\end{tabular}

Two patients developed CSF leak and mild postoperative wound infection which was managed conservatively. No patient developed new onset neurological deficits, bowel or bladder involvement in the post operative period. Three patients were discharged on the second day and 30 patients on the third post operative day. Two patients who developed post operative CSF leak were discharged on the $5^{\text {th }}$ post operative day. All patients started their daily routine activities within one week after surgery.

\section{Discussion}

Faubert C et al. ${ }^{1}$ in 1991 developed the first tubular retractor systems for the access to the lumbar disc. But the steep learning curve and increased rate of complications limited its initial popularity. ${ }^{2}$ Later minimally invasive spine procedures has been established as an alternative to traditional, more aggressive open approaches for the treatment of various spine procedures like disc herniations, spine fractures and spine tumour excision. The proposed advantages of minimally invasive spinal procedures include limited blood loss, reduced tissue destruction, a shorter duration of surgery, a faster postoperative recovery and good post operative outcome according to most of the studies $^{3-7}$

We used small paraspinal incision ranging from 2.5 to $3 \mathrm{cms}$ (Fig. 4) for all MIS cases. Less muscle dissection using tubular retractors did not damaged spinous process or muscle attachment to spine. Excessive dissection, detachment and retraction of paraspinal muscles during open procedures can leads to denervation, atrophy and irreversible muscle injury that destabilizes spinal framework and ultimately cause spinal deformity. MIS procedures are being done utilizing smaller incisions and less muscle dissection using tubular retractors and thereby minimizes iatrogenic soft tissue injury and post operative spinal deformities. ${ }^{8-11}$
Most of the earlier studies found out that MIS techniques associated with steep learning curves, and recommended that surgeons have adequate experience with open procedures before attempting MIS procedures. ${ }^{12-15}$ In our institute, all junior surgeons performed at least one discectomy or pedicle screw fixation independently without much difference in duration or post operative outcome but experienced surgeon with enough experience in open spinal procedures is required for all our spine tumour(IDEM) excision cases. This may be because of the technicality rather than experience which counts for performing MIS pedicle screw fixation and discectomy.

Duration of procedures for MIS cases depends on surgeon experience. On reviewing previous studies it is observed that the duration of procedure varies for various MIS procedures. According to Mannion et $\mathrm{al}^{15}$ and Dahlberg et al. ${ }^{16}$ duration is comparable with open in case of spinal tumour excision whereas it is significantly longer in case of spinal fusion. ${ }^{17-19}$ Intraoperative blood loss in MIS is significantly lower in conventional open approaches as per most of the previous studies but few studies like Lau D et al. ${ }^{20}$ could not find any statistically significant differences between the minimally invasive compared to open microdiscectomy for lumbar disc herniation in terms of operative time, length of stay, neurological outcome, complication rate, or change in pain score. ${ }^{11}$ According to Clark JA et al. ${ }^{21}$ there is level I evidence that supports equivalently good outcomes for tubular microdiscectomy compared with standard microdiscectomy. In our experience blood loss is very mininal (mean values are $105 \mathrm{ml}$ for discectomy, 125 $\mathrm{ml}$ for pedicle screw fixation and $154 \mathrm{ml}$ for IDEM tumour excision) and no patient required blood transfusion. In our experience we found improved post operative pain score after mis procedures. No patients gave a Visual analogue scale(VAS) more than 4 at any point of time after surgery. Most of the patients were discharged on the third post operative day itself and 
they started their daily routine activities within one Week after surgery. All patients were satisfied with 2.5$3 \mathrm{~cm}$ sized small incision. Hence those patients whose back is exposed like saree wearing Indian females may be more satisfied with minimally invasive spinal procedures.

After the early description of minimally invasive fixation of lumbar spine by Magerl et al, ${ }^{22,23}$ Lowery et $\mathrm{al}^{24}$ in 2000 published in detail about percutaneous lumbar pedicle screw fixation device using rods as longitudinal connectors. Pedicle screws provide better stability as it addresses all the three columns of spine. We included 10 cases of minimally invasive percutaneous pedicle screw fixation in the present study. We included cases which require only fixation and those cases which need laminectomy and decompression were not included initially. Later in selected cases we did laminectomy as one of our case was a two level vertebral body fracture (T8 \&L1) for which we did a laminectomy through a separate small midline $2 \mathrm{~cm}$ sized incision (Fig. 4.2) in the lower level(L1).Main drawback faced during minimally invasive pedicle screw fixation was significant $\mathrm{C}$-arm exposure (avarage is 38 shots) associated with the procedure. The number of exposure was very high(64 shots per case) in initial cases but later with experience we could minimize the number of exposure to 25 shots per case. All patients did well during postoperative period and no one developed fresh neurology deficits.

Minimally invasive techniques for the removal of indradural spinal tumors took a lot of modifications over the years. Initially Chiou et al. ${ }^{25}$ used by unilateral approaches for spinal tumours and then Yasargil et al. ${ }^{26}$ described unilateral partial hemilaminectomy for the removal of extra and intramedullary tumours and arteriovenous malformations. Later in 2006, Tredway TL et al. ${ }^{27}$ studied six patients in their novel study, all underwent successful, complete surgical resection of intradural-extramedullary tumors by minimally invasive unilateral approach using a unilateral dilation technique and self-retaining retractor system. Wong AP et al. ${ }^{28}$ directly compared MIS and open approaches for intradural extramedullary tumors and this study was published in 2015. In this retrospective review they included 45 patients treated by open resection or minimally invasive for intradural extramedullary tumors spine tumors and they concluded that intradural extramedullary tumors can be treated by minimally invasive approach, with similar gross total resection, perioperative complication rate, and operative time and less blood loss, shorter hospital stay than open approach. Turel MK et al. ${ }^{29}$ analysed 164 patient and concluded that hemilaminectomy approach for intradural tumors is quick and safe with minimal morbidity and no mortality and in another study 8 cases of anterior and anterolateral IDEM menengiomas were resected safely without causing new neurological deficitsthrough a single-sided keyhole laminotomy. ${ }^{30}$
We included 10 cases of intradural extramedullary spine tumors in this study. We were able to achieve gross total resection in all cases. It took a mean time of 190 minutes from incision to closure and the most time consuming step was perfect dural closure in initial cases. Continuous and interrupted sutures were tried but did not find any difference in post operative outcome. Tissue glue applied after dural closure in all cases. With experience we improved dural closure techniques and saved time in subsequent cases. One case developed post operative csf leak and mild wound infection which was managed conservatively with antibiotics and leak stopped by itself after 3 days without any surgical intervention. No patient developed any fresh postoperative neurological deficits.

\section{Conclusion}

We observed that minimally invasive spine surgery is safe and less destructive. The procedure is fast and associated with minimal morbidity and no mortality. We also noticed that there is increased risk for radiation associated with minimally invasive pedicle screw fixation. There is no significant learning curve associated with pedicle screw fixation or lumbar discectomy but it is significant in case of minimally invasive spine tumour excision.

\section{References}

1. Faubert C, Caspar W. Lumbar percutaneous discectomy, Initial experience in 28 cases. Neuroradiol 1991;33:40710.

2. Oppenheimer JH, DeCastro I, McDonnell DE. Minimally invasive spine technology and minimally invasive spine surgery: a historical review. Neurosurg Focus 2009;27(3):E9.

3. Goald HJ. Microlumbar discectomy: follow-up of 477 patients. J Microsurg 1980;2(2):95-100.

4. Williams RW. Microlumbar discectomy: a conservative surgical approach to the virgin herniated lumbar disc. Spine (PhilaPa1976) 1978;3(2):175-82.

5. Soliman J, Harvey A, Howes G, Seibly J, Dossey J, Nardone E. Limited microdiscectomy for lumbar disk herniation: a retrospective long term outcome analysis. $J$ Spinal Disord Tech 2014;27(1):E8-E13.

6. Porchet F, Bartanusz V, Kleinstueck FS. Microdiscectomy compared with standard discectomy: an old problem revisited with new outcome measures within the framework of a spine surgical registry. Eur Spine J 2009;18(3):360-66.

7. German JW, Adamo MA, Hoppenot RG, Blossom JH, Nagle HA. Perioperative results following lumbar discectomy: comparisonof minimally invasive discectomy and standard microdiscectomy. Neurosurg Focus 2008;25(2):E20.

8. Selznick LA, Shamji MF, Isaacs RE. Minimally invasive interbody fusion for revision lumbar surgery: technical feasibility and safety. J Spinal Disord Tech 2009;22:20713.

9. Kerr SM, Tannoury C, White AP. The role of minimally invasive surgery in the lumbar spine. Oper Techn Orthop 2007; 17:183-89.

10. Foley KT, Holly LT, Schwender JD. Minimally invasive lumbar fusion. Spine 2003;28:26-35. 
11. Foley KT, Gupta SK. Percutaneous pedicle screw fixation of the lumbar spine: preliminary clinical results. $J$ Neurosurg 2002;97(1):7-12.

12. Kan P, Schmidt MH. Minimally invasive thoracoscopic approach for anterior decompression and stabilization of metastatic spine disease. Neurosurg Focus 2008;25:E8.

13. Kerr SM, Tannoury C, White AP. The role of minimally invasive surgery in the lumbar spine. Oper Techn Orthop 2007; $17: 183-89$.

14. Kasis AG, Marshman LAG, Krishna M. Significantly improved outcomes with a less invasive posterior lumbar interbody fusion incorporating total facetectomy. Spine 2009;34:572.

15. Mannion RJ, Nowitzke AM, Efendy J, Wood MJ. Safety and efficacy of intradural extramedullary spinal tumor removal using a minimally invasive approach. Neurosurg 2011:68;208-16.

16. Dahlberg D, Halvorsen CM, Lied B, Helseth E. Minimally invasive microsurgical resection of primary, intradural spinal tumours using a tubular retraction system. Br J Neurosurg 2012:26;472-75.

17. Ghahreman A, Ferch RD, Rao PJ. Minimal access versus open posterior lumbar interbody fusion in the treatment of spondylolisthesis. Neurosurg 2010;66:296-304.

18. Park Y, Ha JW. Comparison of one-level posterior lumbar interbody fusion performed with a minimally invasive approach or a traditional open approach. Spine 2007;32:537-43.

19. Shunwu F, Xing Z, Fengdong Z. Minimally invasive transforaminal lumbar interbody fusion for the treatment of degenerative lumbar diseases. Spine 2010;35:1615-20.

20. Lau D1, Han SJ, Lee JG, Lu DC, Chou D. Minimally invasive compared to open microdiscectomy for lumbar disc herniation. J Clin Neurosci 2011;18(1):81-4.

21. Clark JA, Safaee MM, Khan RN, Brown TM, Foley TF.Tubular microdiscectomy: techniques, complication avoidance, and review of the literature. Neurosurg Focus 2017:43(2);1-9.

22. Magerl F. Injuries of the thoracic and lumbar spine. Langenbecks Arch Chir 352:428-33.

23. Magerl F. External skeletal fixation of the lower thoracic and lumbar spine iUH. In: Stahl E, editor. Current concepts of external fixation of fractures. Berlin: Springer- Verlag 1982:353-66.

24. Lowery GL, Kulkarni S. Posterior percutaneous spine instrumentation. Eur Spine J 2000;9:126-30.

25. Chiou SM, Eggert HR,Laborde G, Seeger W. Microsurgical unilateral approaches for spinal tumour surgery: eight years' experience in 256 primary operated patients. Acta Neurochirurgica 1989;100:127-33.

26. Yasargil MG, Tranmer BI, Adamson TE,Roth P.Unilateral partial hemi-laminectomy for the removal of extra-and intramedullary tumours and AVMs. Advances and Technical Standards in Neurosurgery 1991:18;11332.

27. Tredway TL, Santiago P, Hrubes MR, Song JK, Christie SD, Fessler RG Minimally invasive resection of intradural-extramedullary spinal neoplasms. Neurosurg 2006;58(1):52-8.

28. Wong AP, Lall RR, Dahdaleh NS, Lawton CD, Smith $\mathrm{ZA}$, Wong $\mathrm{RH}$, et al. Comparison of open and minimally invasive surgery for intradural-extramedullary spine tumors. Neurosurg Focus 2015;39(E11).

29. Turel MK, D'souza WP, Rajshekhar R.

Hemilaminectomy approach for intradural extramedullary spinal tumors: an analysis of 164 patients. Neurosurg Focus 2015:39(2);1-6.

30. Kaya RA .Surgical Excition of Spinal Intradural Meningiomas through a Single-Sided Minimally Invasive Approach: Key-Hole Laminotomy. Asian Spine J 2015;9(2):225-31. 